\title{
GROWTH RATES OF THREE REEF-BUILDING CORAL SPECIES IN THE NORTHERN RED SEA, EGYPT
}

\author{
Mohammed M. A. Kotb \\ Marine Science Department, Faculty of Science, Suez Canal \\ University, Ismailia, Egypt
}

Key words : linear growth, coral reefs, Red Sea, Egypt.

\section{ABSTRACT}

Growth rates as linear extensions were measured for three species $T_{\text {of }}$ reef-building corals in four different seasons and at three different depths $(5 \mathrm{~m}, 15 \mathrm{~m}$, and $30 \mathrm{~m})$ in $\mathrm{Na}^{\prime}$ ama Bay, south of Sinai, northern Red Sea, Egypt. Alizarine-Red-S-stain was used as skeletal marker to stain the colonies alive in-situ. Comparison with similar studies elsewhere in the tropical regions shows consistency in growth patterns of the studied species regardless of depth and season, while they were different than others. The estimated annual rates of linear growth for the three corals considered at the different depths $(5 \mathrm{~m}$, $15 \mathrm{~m}$, and $30 \mathrm{~m}$ ) were $9.24,7.48$, and $6.51 \mathrm{~mm} / \mathrm{y}$ for S. pistillata; 6.34 , 9.24 , and $5.90 \mathrm{~mm} / \mathrm{y}$ for $A$. granulosa; and 7.40 and $6.6 \mathrm{~mm} / \mathrm{y}$ for $P$. damicornis, respectively; $P$. damicornis was not found at $30 \mathrm{~m}$ depth. Analysis of the data shows that it is not simple to detect the effect of either temperature or light level on the coral growth and they are simultaneously controlling the coral growth beside other factors, which could interfere as well. The present work could serve as a database for the future environmental monitoring of the marine life in $\mathrm{Na}$ 'ama Bay, which is one of the tourist destinations in the Egyptian Gulf of Aqaba Protectorates.

\section{INTRODUCTION}

Scleractinean corals are considered the major reef builders while the coral reefs are the result of a complex interaction of constructive processes that build solid framework, and destructive processes that alter and remove that material. Of primary importance in understanding the overall forces that shape the reef, is a quantification of the individual contributions made by the carbonate- 
producing organisms that live in and on it (Sheppard \& Ssheppard. 1991).

Skeletal grouth of stony corals is one of the important ecological and biological subjects. which essentially can help as an indicator for the calcification rate of the reef. Measurements of skeletal linear extension (LE) of corals within a distinct period by means of skeleton markers are one of the methods used (Rahav et al., 1991; and Dullo ef al. 1995). These markers indicate the beginning of the newly grown sheletal extension during the time interval. Several methods have been used such as, plastic coated wires (Charuchinda \& Hylleberg, 1984; and Oliver, 1984), Alizarin-Red-Sstain in order to stain the respective coral colonies alive (i.e. Gladfelter, 1984; and Dullo et al., 1995), spikes were also driven into the coral skeletons as markers (Shinn, 1976), and direct interval photographs of the coral colonies have been used (Rahav et al., 1991) as well. A variety of different methods have been used especially to measure the width of the annual growth rings in massive corals as an indicator of LE such as, X-ray (Gladfelter, 1984; Logan \& Tomascik, 1991; Fang \& Chou, 1992; and Bosscher, 1993).

One of the most conspicuous and universal aspects of coral growth is its variability (Buddemeier \& Kinzie, 1976). The physiology of growth and skeletal deposition by scleractinian corals has been the subject of experimentation and speculation for more than a hundred years (Chalker, 1983). It is known that anuual coral growth can be affected by different physical factors such as temperature (Gladfelter, 1984; and Vago et al. 1997), light and depth "as a function of light intensity" (Strömgren, 1987; Gattuso et al. 1993; and Dullo et al., 1995), salinity (Charuchinda \& Hylleberg, 1984), sedimentation rates (Yap \& Gomez, 1981), water movements (Brown et al., 1985), predation (Richmond \& Hunter, 1990), and oil pollution (Dodge et al., 1984). In addition coral growth may be affected by biological factors, e.g. food availability (Dullo ef al., 1995), endogenous zooxanthellae rhythms (Gattuso et al., 1993; and Dullo et al., 1995) and reproductive cycies (Richmond \& Hunter, 1990).

Normally, the interference of a complex set of factors, either biotic or abiotic, is responsible for the skeletal deposition and growth mechanisms (Buddemeier \& Kinzie, 1976; Logan \& Tomascik, 1991; and Dullo et al., 1995), which makes it diffecult to investigate the effect of each factor separately. 
The present study aims to investigate the growth rate of three of the most dominant scleractinian coral species in the Red Sea. In addition. the study attempts to throw light on the effects of the major environmental conditions (i.e. light and temperature) on their grouth in different seasons and at different depths. Such effects are obscured if growth is integrated over the whole year. It is worth to mention that the present study follow's the same procedures used by Kotb (1996). where the same experiment was done during 1992. and this allow's to follow and monitor the growth rates of the respective species since that time.

\section{MATERIALS AND METHODS}

The study covers growth increments of three coral species namely: Stylophora pistillata (Esper, 1797); Pocillopora damicornis (Linnaeus, 1758); and Acropora granulosa (Edwards \& Haime, 1860), which are predominant in the northern Red Sea reefs especially in the Egyptian region. Growth rates as LE of the investigated species at different depths $(5 \mathrm{~m}, 15 \mathrm{~m}$ and $30 \mathrm{~m})$ were measured during the different seasons of 1998 for the purpose of comparison.

Study area:

The study was conducted on the fringing reef of $\mathrm{Na}$ 'ama Bay along the south-eastern coast of the Sinai Peninsula (Fig.1). The bay is located near Sharm El-Shiekh on southern Sinai, facing the Red Sea proper. This area is a typical example of a Red Sea fringing reef (Sheppard \& Sheppard, 1991). The site experiences an intermediate level of exposure to waves and has fairly low sedimentation in shallow waters. The fore-reef is covered with a dense cover of corals while the back-reef and the reef slope are relatively impoverished (Dotan, 1990).Two sandy plates interrupt the reef slope at $5 \mathrm{~m}$ and $15 \mathrm{~m}$ depths. The depth level of $30 \mathrm{~m}$ experiences poor light conditions due to the steep slope angle and its orientation towards the west (Kotb, 1996).Dense communities of fishes usually inhabit the sandy plate at $15 \mathrm{~m}$ depth (especially trigger and surgeon fishes).

Staining method:

The living coral colonies were stained in situ with AlizarinRed-S-stain. Staining periods of 4 hours as recommended by some authors (Dustan, 1975 and Gladfelter et al., 1978) gave no coloured 
marks in the coral skeletons. After a pilot experiment. a staining period of $24 \mathrm{~h}$ was found to be suitable for marking the skeletons.

Three to Five colonies of each species at each depth $(5 \mathrm{~m} .15 \mathrm{~m}$ and $30 \mathrm{~m}$, were collected and stained at the respective depth of collection. Colony size varied from $101015 \mathrm{~cm}$ in diameter and the corals were removed from the bottom with great care. For the underwater staining procedure. plastic bags each with 25 litres capacity were prepared with $0.25 \mathrm{~g}$ of stain, which was securely tied off in one of its corners. The colonies were placed in the plastic bag. which was fully inflated to ensure that it contained 25 litres of seawater. Then it was tightly closed with cotton string and the stain was allowed to release from the comer of the bag and mix with the water inside it by shaking the bag slowly once or twice, taking care not to damage the colonies inside. The final concentration of the stain in the bags was about $10-15 \mathrm{mg} / \mathrm{I}$ seawater, as used by Dustan (1975) and Gladfelter et al. (1978).

Afterwards, the plastic bags were securely fixed with strings to a protected location on the bottom for $24 \mathrm{~h}$ (colonies were in the normal growth position). Then colonies were carefully removed from the bags and tied to a horizontal aluminium rod, which was fixed to the bottom at the respective depth (Fig.2). The stained corals were allowed to grow for a period of about 3 months (i.e. a season). This procedure was carried out repeatedly at each season during 1998. The season timing followed the investigation of Kotb (1996) for the sake of data comparison being; $53,95,88$, and 86 days for winter, spring, summer, and autumn respectively.

Preparation of skeletons and growth measurements:

After each growth period, corals were taken out of water and macerated in closed plastic containers containing seawater for one week. The remaining tissues were removed from the skeleton with a fresh water jet, and then the skeleton was air-dried. Skeleton added during the growth period appeared as a white portion at the tip of each branch over the old pink skeleton, due to staining process (Fig. 3). The rate of linear extension (LE) of the newly grown skeleton was determined for each species in each season at each depth and the means of LE [mm / day] were calculated.

LE measurements were taken as the mean of $n=$ (individual measurements of 10 branches per colony and $3-5$ colonies per species). Branches were selected randomly and sectioned longitudinally into 2 halves along the vertical growth axis of the 
branch. using a diamond saw (width of blade $0.3 \mathrm{~mm}$ ). Distances between the staining mark and the edge of the newly grown material were measured (Figure 4) using a dissecting microscope with ocular micrometer. Three measurements of LE were taken along the growth direction of each branch and the longest was recorded (Fig. 4). The seasonal mean LE rates were calculated as mmiday for each season. It should be noted that annual growth data were collected over a period of 322 days. Finally, the LE rate was extrapolated for the whole year for each species at each depth by adding the 4 means of seasonal growth figures. The "growth rate" used in the present work means the "linear extension rate (LE)" and the vice versa.

\section{Other measured parameters:}

Bottom temperatures were measured weekly at the respective depths, during inspection dives over the investigation period using a norrnal laboratory mercury thermometer.

Plankton samples were collected monthly from the water surface in the study area (from February 1998 to January 1999). Their abundance per $\mathrm{m}^{3}$ of seawater was recorded and plotted to show the monthly variations and peaks of plankton abundance in the area.

\section{Statistical treatment of data:}

LE rates of the respective scleractinian corals were compared with reference to depth and season. Furthermore, comparison of the whole year growth of the different species at different depths was also investigated.

Data of LE for each species were tested in each season at each depth, to satisfy the normality and homogeneity of variance assumptions. One-way analysis of variance (ANOVA) was applied to test significant differences in the LE data between different species in different seasons and depths. Where the F-value given by ANOVA was significant, a Bonferroni multiple comparison test of the post-hoc contrasts with a significance level of 0.05 was used to indicate which groups of seasons or depths are differed significantly.

It is worth to mention here that the "growth rate" used in the present work means the "linear extension rate (LE)" and the vice versa.

\section{RESULTS}

Table (1) gives the monthly temperature fluctuations at the various depths, as well as the planktonic abundance at the surface water of the study site. Temperatures presented a normal profile of highest values 
during summer and lowest values during winter (Figure 5). However. seasona! temperature did no: vary over depth except for the $30 \mathrm{~m}$ station, where a decrease was observed in spring and autumn.

The annual distribution of plankton (No. of individuals $/ \mathrm{m}^{3}$ seawater) at the water surface in the study area showed four peaks over the year (Figure 6). One peak occurred at the end of each season. The highest peak was in winter, while the lowest one was in summer.

The LE grouth rates obtained in this study are summarised in Table (2) with the maximum and minimum recorded values. It is worth to mention that $P$. damicornis was the only species not occur at $30 \mathrm{~m}$ depth in the study site.

\section{Stylophora pistillata:}

S. pistillata showed its highest growth rates during the warm periods of summer and autumn at the shallowest depth of $5 \mathrm{~m}$ (Fig.7), while at the cold periods of winter and spring, the highest growth rates were at the intermediate depth of $15 \mathrm{~m}$. The analysis of variance (ANOVA) revealed that there are statistically significant differences $(p<0.05)$ in the growth rates of $S$. pistillata among depths in all seasons except in winter according to Bonferroni test (Table $3 \mathrm{~A}$ ). Furthermore between seasons, the growth rate at $5 \mathrm{~m}$ depth was significantly higher in summer than in other seasons, while at $15 \mathrm{~m}$ depth, growth showed the significantly highest rates in spring (Table $3 \mathrm{~B}$ ).

\section{Pocillopora damicornis:}

$P$. damicornis had almost similar growth patterns at 5 and $15 \mathrm{~m}$ depths during the different investigated seasons (Fig. 8). The seasonal growth rates at each depth were alike and ANOVA test showed no significant differences among the measured rates (Table 4B).

\section{Acropora granulosa:}

A. granulosa showed variable growth rates at the different depths during the studied seasons (Fig. 9) with two peaks of growth in autumn and spring. The growth pattern of this species was significantly higher at $15 \mathrm{~m}$ depth than the shallower depth of $5 \mathrm{~m}$ in all seasons. ANOVA test had detected significant differences in the growth rates between depths during different seasons, and Bonferroni test gave these depths (Table $5 \mathrm{~A}$ ). Generally, the $30 \mathrm{~m}$ depth showed significantly lower growth rates than $15 \mathrm{~m}$ depth in all seasons except in winter, while the growth at both $5 \mathrm{~m}$ and $15 \mathrm{~m}$ did not differ significantly except in summer (Table $5 \mathrm{~A}$ ). Furthermore, there were significant differences between the growth rates of $A$. granulosa in the studied seasons at each depth ((Table 5B). 
GROWTH RATES OF THREE REEF-BULDING CORAL I:I SPECIES IN THE NORTHERN RED SEA, EG YPT

Annual growth of the studied species:

Table (6) presents the annual growth data, as accumulated values from the seasonal growth rates for each species at each depth. The table also includes the numbers of replicates $(N)$ for each species at each depth.

Growth ratis according to depth and species showed usual patterns, with higher rates in shallow water and decreased by depth for both S. pistillata and P. damicornis (Fig.10), while A. granulosa had different pattern with highest growth rate at the intermediate depth (i.e. $15 \mathrm{~m}$ ). The highest growth rates were recorded for $S$. pistillata and $A$. granulosa at $5 \mathrm{~m}$ and $15 \mathrm{~m}$, respectively (Table 6 ), while the highest growth rate at $30 \mathrm{~m}$ depth was recorded for $S$. pistillata.

\section{DISCUSSION}

The growth rates obtained in the present study showed different pattern than that recorded in other areas. Loya (1985) studied the LE of $S$. pistillata in the northern Gulf of Aqaba and he recorded lower LE of almost $0.003 \mathrm{~mm} /$ day in summer and $0.001 \mathrm{~mm}$ /day in winter at $5 \mathrm{~m}$ depth, than the recorded rate in the present study $(0.035$, and $0.019 \mathrm{~mm} /$ day, respectively). Glynn (1977) studied the growth rate of $P$. damicornis within $7 \mathrm{~m}$ depth in the Gulf of Panama and the Gulf of Chiriqui (Pacific coast of Panama). He found mean annual growth of 3.08 and $3.86 \mathrm{~mm} / \mathrm{y}$ respectively and related that higher growth to the higher temperature in the Gulf of Chiriqui. His growth data are much lower than the present work values for the same species $(6.53$ and $5.75 \mathrm{~mm} / \mathrm{y}$, at 5 and $15 \mathrm{~m}$, respectively).

On the other hand, the present results of the growth rates are similar to those recorded by Kotb (1996), while there was considerable variation between the maximum and minimum growth values of each species at the same depth and in the same season. The earlier findings of other authors, e.g. Isdale (1977) and Strömgren (1987), may help to explain these differences. These authors found that colonies of the same species may grow at different rates at the same depth and time, depending on the surrounding conditions.

Temperature in the study area showed normal patterns of variation at such latitudes, and similar seasonal variations have been 
recorded in the area by Hulings (1979); Dotan (1990): and Kotb (1996). Fricke and Schuhmacher (1983) found that light intensity along the Sinai coast on the Red Sea varied seasonally and decreased with depth to about $80 \%, 60 \%$ and $50 \%$ of the surface light intensity at $10 \mathrm{~m}, 20 \mathrm{~m}$ and $30 \mathrm{~m}$ respectively. A marked drop in water transparency was reported in February-March due to increased plankton productivity (Levanon-Spanier et al. 1979: and Fricke \& Schuhmacher, 1983). This phenomenon was confirmed by the fieldwork in this study, where the highest levels of temperature and light could be recorded in summer and lowest levels in winter.

The $L E$ rates of $S$. pistillata at $5 \mathrm{~m}$ depth tend to follow the patterns of temperature and light over the year. LE rates increased with increasing temperature level and light intensity. Conversely at $15 \mathrm{~m}$ depth, the pattern of LE rates was inversely affected by temperature and light profiles (with the highest rate in spring).

The reproduction of S. pistillata in the Gulf of Aqaba and the Red Sea has been observed during the period of December-July by some authors (e.g. Loya, 1985; and Richmond \& Hunter, 1990). Also, the reproduction time of one species may differ with depth within the same reef coral community (Richmond \& Hunter, 1990). Therefore, the more probable explanation is that $S$. pistillata reproduced between December and July, but not simultaneously at the different depths. Reproduction could take place in winter at $5 \mathrm{~m}$ depth, and in summer at $15 \mathrm{~m}$ depth. At the times concerned, the colonies invested their energy in reproduction mechanisms rather than in growth.

Furthermore, the effects of the hard winter conditions (i.e. low temperature, low light intensity and water turbulence caused by waves) should not be ignored. They affect the shallowest depth more than the deeper depths. Therefore, the LE rate of S. pistillata at $5 \mathrm{~m}$ depth was lower in winter than in the other seasons. In contrast, the more favourable light and temperature conditions lead to the highest LE rate in summer at that depth. This could provide further evidence that the LE rate depends on light and temperature. These conclusions are in accordance with Kotb (1996) who found the same variation of growth with depth.

$P$. damicornis had its highest $L E$ at $5 \mathrm{~m}$ depth in autumn and lowest in winter. This autumn trend reveals that high temperatures and light intensity in summer may have inhibited growth at those shallow depths. The lowest growth rate in winter may be due to the 
rough uinter conditions. Davies (1991) had similar pattern of growth when he studied the effect of light intensity on the energy budgets of $P$. damicornis at $3 \mathrm{~m}$ depth in Hawaii. He found that the coral energy budget increases with increasing light.

An overview of the growth at all depths in all seasons shows different patterns between the studied species. However, it is meaningful to say that each species reacts differently to the surrounding conditions.

At $5 \mathrm{~m}$ depth. $S$. pistillara skeletons grew more rapidly in terms of linear extension than the other species during harsh winter conditions and during the most favourable conditions of summer (i.e. highest illumination levels and temperatures). On the other hand, the three species showed similar skeletal extensions at the same depth in autumn and spring searons with moderate illumination levels and temperatures. Therefore, it can be deduced that $S$. pistillata could survive more successfully in extreme conditions than $P$. damicornis and $A$. granulosa. On the other hand, the highest recorded $L E$ rate at $15 \mathrm{~m}$ depth in all seasons except winter was for $A$. granulosa. Also, it may be deduced that $A$. granulosa preferred the depth of $15 \mathrm{~m}$, which receives sufficient light for photosynthesis production and is away from the water turbulence at the surface. The fact that $A$. granulosa had the lowest LE rate of all the species in winter may suggest that $A$. granulosa is the most sensitive species to harsh winter conditions.

As mentioned before, temperature was similar along the depth profile over the year. Therefore, light intensity was the major environmental factor varied by depth. The annual growth patterns of the species with reference to depth could be related directly to light intensity differences.

Each species exhibited similar relationship between light intensity and both seasonal and annual growth. The annual $L E$ rates of S. pistillata and $P$. damicornis decreased with depth, accordingly, the LE mechanism of these species may depend on light. $A$. granulosa reached its highest annual LE rate at $15 \mathrm{~m}$ depth, which may indicate that $A$. granulosa needs moderate light conditions (as at $15 \mathrm{~m}$ depth) for its maximum extension rate. Gladfelter (1984) showed through a series of lab experiments on $A$. cervicornis that LE occurred as results of micritic crystals, which were deposited more at night than in the daytime. She concluded that temperature controlled the IE mechanism more than light. 
Comparing the annual grouth rates. A. granulosa and $S$. pistillara had the highest annual LE of $9.24 \mathrm{~mm} / \mathrm{y}$. It is noticeable that A. granulosa and S. pistillata grew more successfully in the study area than $P$. damicornis. The dominance of both species over the $P$. damicornis in the Egyptian Red Sea reefs was.recorded by Kotb et al. (1991) in Ras Mohamed reefs and by Kotb el al. (2000) in the southern reefs of Egypt from Hurghada until the Egypu/Sudan borders.

From the present study it is obvious that several factors govern the skeletogenesis of the corals $S$. pistillata, $P$. damicornis and $A$. granulosa in varying degrees. Therefore, perhaps a better insight on the processes of linear extension and calcium carbonate accretion involved in the growth of the skeletons could be reached by longerterm investigations (i.e. over several years), using a larger number of test samples and by bathymetrical exchange of cloned colonies.

\section{CONCLUSIONS}

Finally, it could be concluded that light and temperature control the linear extension growth of corals simultaneously, while other factors such as reproduction may interfere to some extent. Furthermore, high light intensity and temperature may inhibit the LE growth of corals.

\section{REFERENCES}

Bosscher,H.(1993).Computerized tomography and skeletal density of coral skeletons. Coral Reefs..12: 97-103.

Brown, B.E.; Sya'rani, L. and Le Tissier,M.D.A. (1985). Skeletal form and growth in Acropora aspera (Dana) fron Pulau Seribu, Indonesia. J.Exp. Mar. Ecol., 86:139-150.

Buddemeier, R.W.\& Kinzie III, R.A.,(1976).Coral growth. Oceanogr. Mar. Biol. Ann. Rev., 14: 183-225.

Chalker, B. E. (1983).Calcification by corals and other reef animals. In Perspectives on Coral Reefs," Barnes. D. J. (ed.), Aust. Inst. Mar. Sci., 29-45. 
Charuchinda M. and Hylleberg. J.(1984). Skeletal extension of Acropora formosa at a fringing reef in the Andaman Sea. Coral Reefs.. 3: $215-219$.

Davies. P.S. (1991). Effect of daylight variations on the energy budgets of shallow-water corals. Mar Biol..J08:137144.

Dodge, R.E.: Wyers.S. C.; Frith, H. R.: Knap. A. H.; Smith. S. R.\& Sleeter. T. D. 1984. The effects of oil and oil dispersants on the skeletal growth of the hermatypic coral Diploria strigosa. Coral Reefs, $3: 191-198$.

Dotan, A. (1990). Population structure of the echinoid Heterocentrotus mammillatus (L.) along the littoral zone of south-eastern Sinai. Coral Reefs.,9: 75-80.

Dullo, W.;Gektidis,M.; Golubic, S.; Heiss, G. A.; Kampmann, H.; Kiene, W.; Kroll, D. K.; Kuhrau, M. L.; Radtke, G.; Reijmer, J. G.; Reinicke,G. B.; Schlichter, D.; Schuhmacher, H.; Vogel, K. (1995). Factors controlling Holocene reef growth : An interdisciplinary approach. Facies., 32:145-188.

Dustan, P. (1975).Growth and form in the reef-building coral Montastrea annularis. Mar. Biol., 33 : 101-107.

Fang, L. \& Chou, Y. (1992). Concentration of fulvic acid in the growth bands of hermatypic corals in relation to local precipitation. Coral Reefs., 11:187-191.

Fricke, H.W.\& Schuhmacher, H.(1983). The depth limits of Red Sea stony corals : An ecophysiological problem (A deep diving survey by submersible). Mar. Ecol., 4 (2): $163-194$.

Gattuso, J. P.; Yellowlees, D. \& Lesser, M. (1993).Depth and light dependent variation of carbon partitioning and utilization in the zooxanthellate scleractinian coral 
Stylophora pistillata. Mar. Ecol. Prog. Ser. 9? : 267-276.

Gladfelter,E.H.(1984).Skeletal development in Acropora cervicornis : III- A comparison of monthly rates of linear extension and calcium carbonate accretion measured over a year. Coral Reefs., 3:51-57.

Gladfelter, E. H.; Monahan, R. K. and Gladfelter, W. B.. (1978). Growth rates of five reef-building corals in the northeastern Caribbean. Bull. Mar. Sci., 28: (4), 728-734.

Glynn,P. W.(1977).Coral growth in upwelling and nonupwelling areas off the Pacific coast of Panama. J. Mar. Res., 35 (3) : 567-585.

Hulings, N. C.(1979).Currents in the Jordan Gulf of Aqaba. Dirasat, $6: 21-33$.

Isdale, P. J.(1977). Variation in growth rate of hermatypic corals in a uniform environment. Proc. 3 rd Int. Coral Reef Symp., 2 : 403-408.

Kotb, M. M.A.(1996). Ecological and biological studies on the coral reefs at southern Sinai coasts, Red Sea, Egypt. Ph. D.thesis, Marine Science Department, Faculty of Science, Suez Canal Univess.

Kotb, M. M. A.; Abou Zeid, M. M.; Hanafy, M. H.(2000). Overall evaluation of the coral reef status along the Egyptian Red Sea coast. Conference of the Italian Society of Marine Biology ( $31^{\circ}$ SIBM), 13-20 May 2000, Sharm El-Sheikh, Egypt (in press).

Kotb, M. M.A.;Hartnoll, R.G and Ghobashy, A. F. (1991). Coral Reef community structure at Ras Mohammed in the northern Red Sea. Tropical Zoolcgy': 4: 269285 . 
GROWTH RATES OF THREE REEF-BUILDING CORAL 177 SPECIES IN THE NORTHERN RED SEA, EGYPT

Levanon-Spanier, 1.: Padan. E. and Reiss. Z.(1979). Primary production in a desert-enclosed sea-the Gulf of Elat (Aqaba). Red Sea. Deep-Sea Res.. 26: 673-685.

Logan, A and Tomascik, T.(1991). Extension growth rates in two coral species from high-latitude reefs of Bermuda. Coral Reefs.. J0:155-160.

Loya, Y. (1985). Seasonal changes in growth rate of a Red Sea coral population. Proc. 5th Int. Coral Reef Cong., Tahiti., $6: 187-191$.

Oliver, J.K. (1984). Intra-colony variation in the growth of Acropora formosa : Extension rates and skeletal structure of white (zooxanthellae-free) and browntipped branches. Coral Reefs., 3:139-147.

Rahav, O.; Ben-Zion, M.; Achituv, Y. \& Dubinsky, Z. (1991). A photographic, computerized method for in situ growth measurements in reef building cnidarians. Coral Reefs., $9: 204$.

Richmond, R. H.and Hunter, C.L.(1990). Reproduction and recruitment of corals : Comparisons among the Caribbean, the tropical Pacific, and the Red Sea. Mar. Ecol. Prog. Ser., 60 :185-203.

Sheppard, C.R.C \& Sheppard, A.L S.,1991.Corals and coral communities of Arabia. Fauna of Saudi Arabia, 12: $170 \mathrm{pp}$.

Shinn,E.A.(1976).Coral reef recovery in Florida and the Persian Gulf. Env. Geol., I :241-254.

Strömgren, T.(1987). The effect of light on the growth rate of intertidal Acropora pulchra (Brook) from Phuket, Thailand, lat. $8^{\circ} \mathrm{N}$. Coral Reefs, $6: 43-47$. 
Vago,R.;Dubinsky, Z.;Genin. A.;Ben-Zion. M.\& Kizner. Z.(1997) Growth rates of three symbiotic corals in the Red Sea. Limnol. Oceanogr., 42 (8):1814-1819.

Yap, H.T. and Gomez, E. D.(1981). Growth of Acropora pulchra (Brook)in Bolinao, Pangasinan, Philippines. Proc. 4th Int. Coral Reef Symp., 2 :207-213. 


\section{GROWTH RATES OF THREE REEF-BULDING CORAL SPECIES IN THE NORTHERN RED SEA, EGYPT}

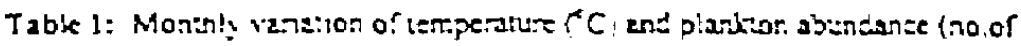

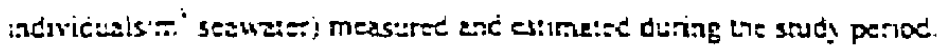

\begin{tabular}{|c|c|c|c|c|}
\hline \multirow{2}{*}{ Mon'ss } & \multicolumn{3}{|c|}{ Tetipeaiuse } & \multirow{2}{*}{$\begin{array}{l}\text { Plankion } \\
\text { ebundance }\end{array}$} \\
\hline & $5 \pi$ degin & $15 \mathrm{mc} c=3: \mathrm{h}$ & $50 \mathrm{mdeg} h$ & \\
\hline Tar? & 18 & $: 8$ & 18 & 274 \\
\hline Fes & 21 & $2 !$ & $2 !$ & 500 \\
\hline Vaz & 22 & 22 & 22 & 1800 \\
\hline AD: & 22 & 22 & 22 & 410 \\
\hline $\mathrm{Mat}$ & 25 & 25 & 20 & 157 \\
\hline Iu? & 26 & 26.5 & 20 & 1118 \\
\hline Jut & 28 & 28 & 28 & 41 \\
\hline Aur & 26 & 26 & 26 & 516 \\
\hline SeD & 26 & 26 & 26 & 736 \\
\hline $\mathrm{Ost}$ & 25 & 25 & 25 & 160 \\
\hline Nor & 22 & 22 & 20 & 368 \\
\hline $10 e c$ & 18 & 18 & 18 & 1048 \\
\hline
\end{tabular}

Table 2: Mean linear exiension (1.E) rales of :he studied species with reference to depths and sersons. 1.5 - mmiday and all the values are \pm SD, white $\mathrm{N}$-number of sampled branches. The sign ( - ) indicale that no dala due to the absence of this species at that depth.

\begin{tabular}{|c|c|c|c|c|c|c|c|c|c|c|c|c|c|}
\hline \multirow{2}{*}{ Seasan } & \multirow{2}{*}{\begin{tabular}{|c|} 
Species \\
Depth \\
\end{tabular}} & \multicolumn{4}{|c|}{ I pissilloro } & \multicolumn{4}{|c|}{ P. danticernis } & \multicolumn{4}{|c|}{ A gramulasa } \\
\hline & & mean LE & Max. & $\operatorname{Min}$ & $N$ & mean l.E & Max & $\mathrm{Min}$. & $\mathrm{N}$ & mean LI: & Max. & Min. & $N$ \\
\hline \multirow{3}{*}{ Summer } & $5 \mathrm{~m}$ & $0.035=0.01$ & 0.08 & 0.02 & 50 & $0.021 \leq 0.01$ & 0.06 & 0.01 & 45 & $0.016 \pm 0.01$ & 0.04 & 0.01 & 50 \\
\hline & $15 \mathrm{~m}$ & $0.016=0.01$ & 0.03 & 0.01 & 39 & $0.018=0.01$ & 0.06 & 0.01 & 47 & $0.028 \pm 0.01$ & 0.06 & 0.02 & 48 \\
\hline & $30 \mathrm{~m}$ & $0.020 \pm 0.01$ & 0.07 & 0.01 & 47 & - & - & $=$ & -1 & $0.012 \pm 0.0$ & 0.03 & 0.01 & 50 \\
\hline \multirow{3}{*}{ Aciunn } & $5 \mathrm{~m}$ & $0.027=0.01$ & 0.06 & 0.03 & 39 & $0.025=0.01$ & 0.04 & 0.02 & 45 & $0.025 \pm 0.01$ & 0.04 & .01 & 47 \\
\hline & $15 \mathrm{~m}$ & $0.019 \pm 0.01$ & 0.03 & 0.01 & 44 & $0.021=0.01$ & 0.04 & 0.01 & 44 & $0.033 \pm 0.01$ & 0.06 & 0.02 & 39 \\
\hline & $30 m$ & $0.021=0.01$ & 0.05 & 0.01 & 46 & - & $=$ & - & - & $0.022+0.01$ & 0.05 & 0.01 & 50 \\
\hline \multirow{3}{*}{ Winter } & $5 \mathrm{~m}$ & $0.019 \pm 0.01$ & 0.04 & 0.01 & 48 & $0.017=0.01$ & 0.03 & 0.01 & 48 & $0.008+0.0$ & 0.03 & 0.01 & 44 \\
\hline & $15 n$ & $0.023=0.0$ & 0.03 & 0.01 & 33 & $0.019=0.01$ & 0.03 & 0.01 & 48 & $0.0: 3 \div 0.01$ & 0.04 & 0.02 & 47 \\
\hline & $30 \mathrm{~m}$ & $0.018 \pm 0.01$ & 0.04 & 0.01 & 49 & - & 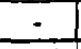 & - & - & $0.018 \pm 0.01$ & 0.04 & 0.01 & 50 \\
\hline \multirow{3}{*}{ Spring: } & Sin & $0.024=0.01$ & 0.05 & 0.01 & 39 & $0.021=0.01$ & 0.03 & 0.01 & 47 & $0.023 \pm 0.01$ & 0.05 & 0.02 & 30 \\
\hline & $15 \mathrm{~m}$ & $0.027 \pm 0.01$ & 0.04 & 0.01 & 48 & $0.017=0.0$ & 0.03 & 0.01 & 49 & $0.031 \pm 0.02$ & 0.07 & 0.01 & .13 \\
\hline & $30 \mathrm{~m}$ & $0.015 \div 0.01$ & 0.03 & 0.01 & 47 & $=$ & $\dot{-}$ & - &. & $10.019 \pm 0.01$ & 0.04 & 0.02 & 48 \\
\hline
\end{tabular}

Tahle 3 : Bonferooni multiple comparison tesi bif the post-lioe contrasts for ti pixtillutu biweel $A$ ) mean growilh rates for depths at cach seasun, and B) seasonal brouth rates at ench dipth. Nis=no significant difterence. "-significitut $(/<0.05)$ difterer.ec.

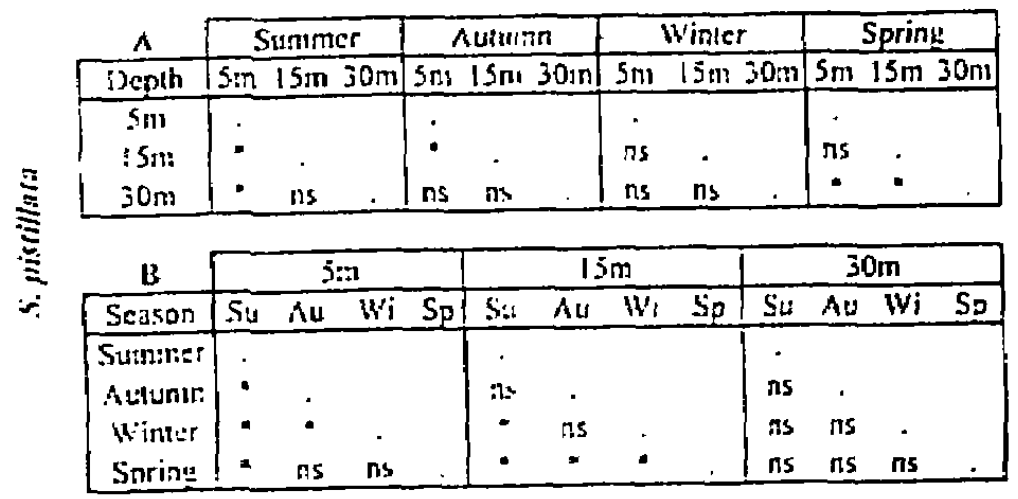


Table 4 : Bonferroni multiple compatison test of the post-toc contrasts for $P$ damicornis between: $\Lambda$ ) mean grouth, rates for depths a: eaci, season, and $B$ ) seasonal growth rates at each depth. Ns-no significan differenec. "msigrificant $(P<0,05)$ difference.

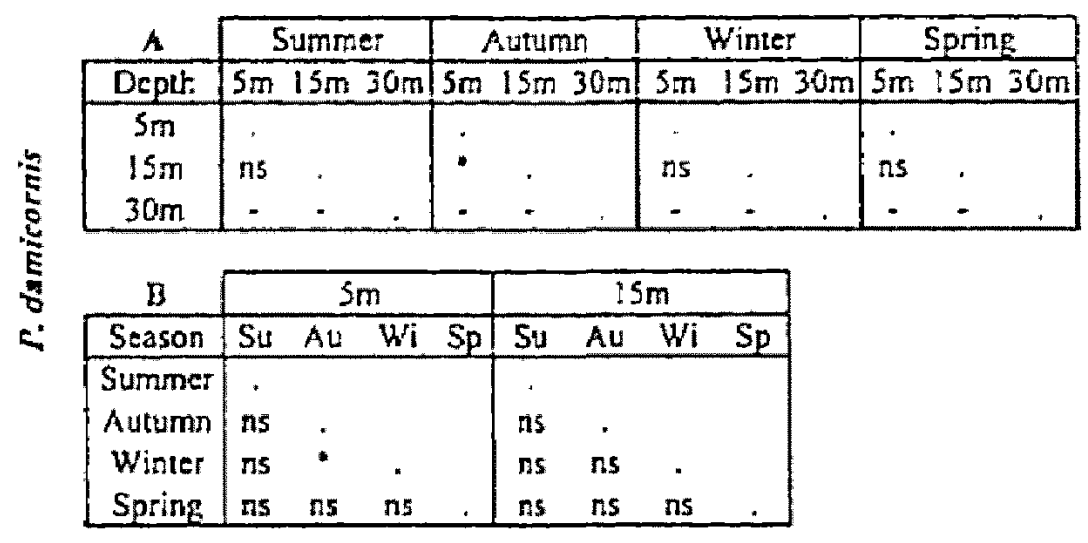

Table 5 : Bonferroni multiple comparison test of the post-hoc contrasts for $A$. ganulosa between: A) mean growth rates for depths at each season, and B) seasonal growth rates at each depth. Ns=no signifieant difference, $*=$ significant $(P<0.05)$ difference.

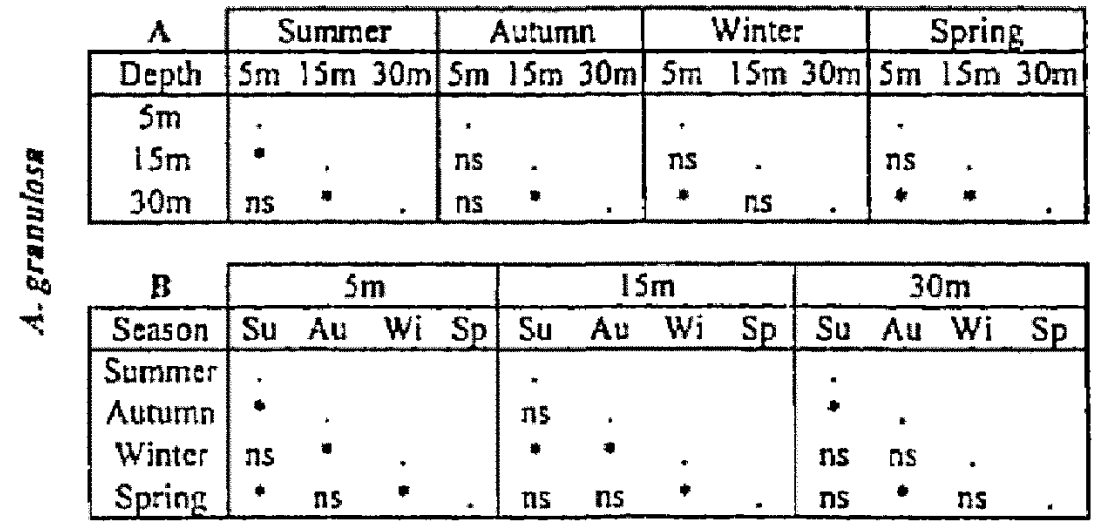

Table 6: The annual linear extension (LE) rates of the studied spectes at different depths. LE $=\mathrm{mm} / y_{1} \lambda=$ number of measured branch tips, and (.) indicate that no data .

\begin{tabular}{|c|c|c|c|c|c|c|}
\hline Depth & S. pistillata & N & P. damicornis & N & A. gramulosa & N \\
\hline $5 \mathrm{~m}$ & 9.24 & 176 & 7.392 & 185 & 6.336 & 180 \\
\hline $15 \mathrm{~m}$ & 7.48 & 164 & 6.6 & 188 & 9.24 & 177 \\
\hline $30 \mathrm{~m}$ & 6.512 & 189 & & & 5.896 & 198 \\
\hline
\end{tabular}


GROWTH RATES OF THREE REEF-BUILDNG CORAL I\$1 SPECIES IN THE NORTHERN RED SEA, EGYPT

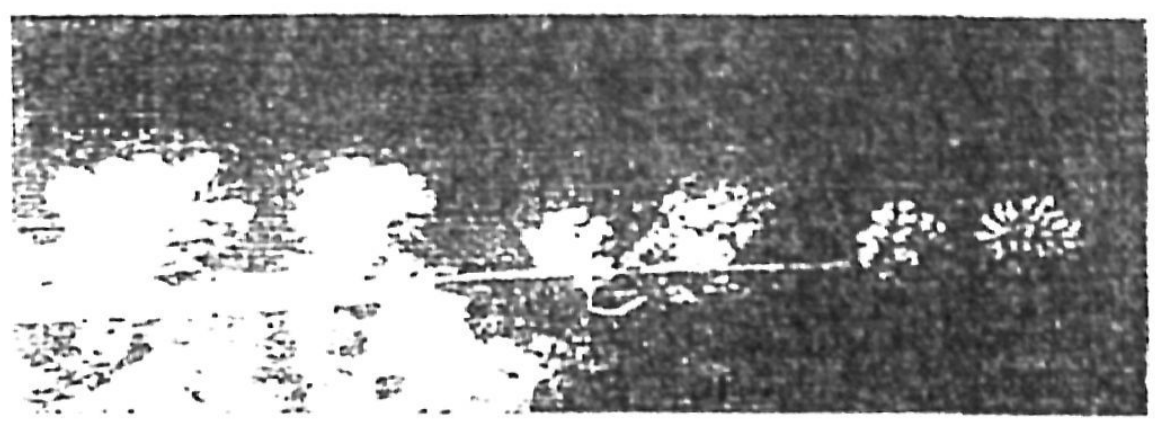

$1121: 11:$
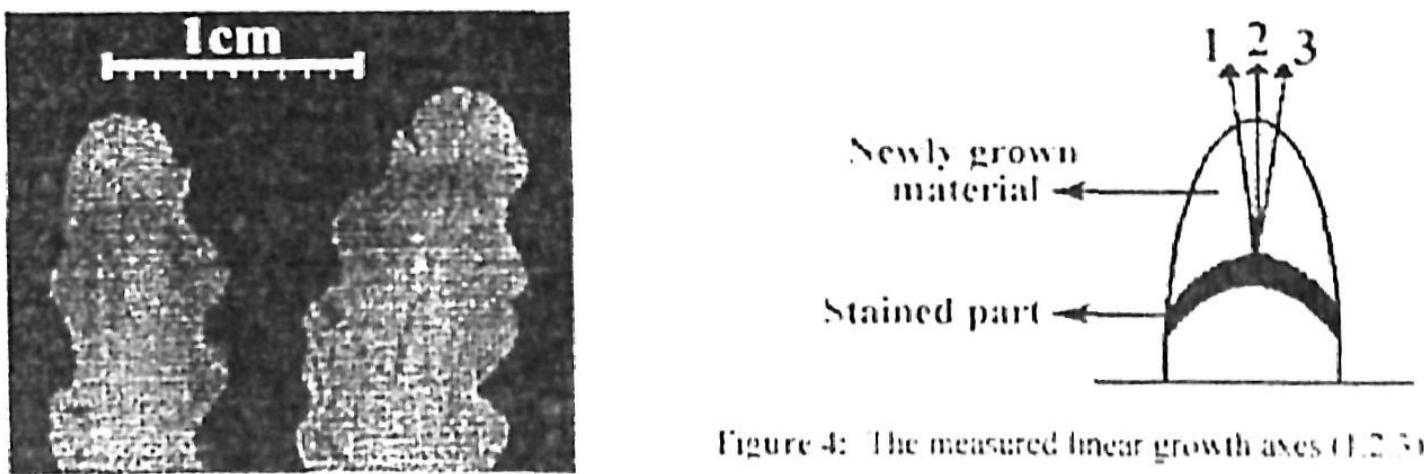

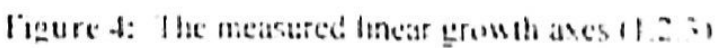

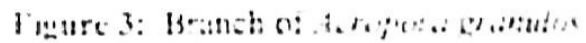

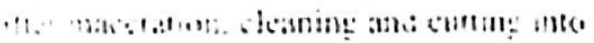

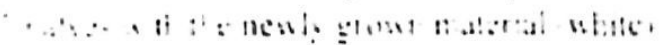

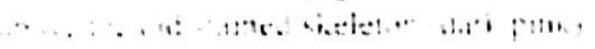




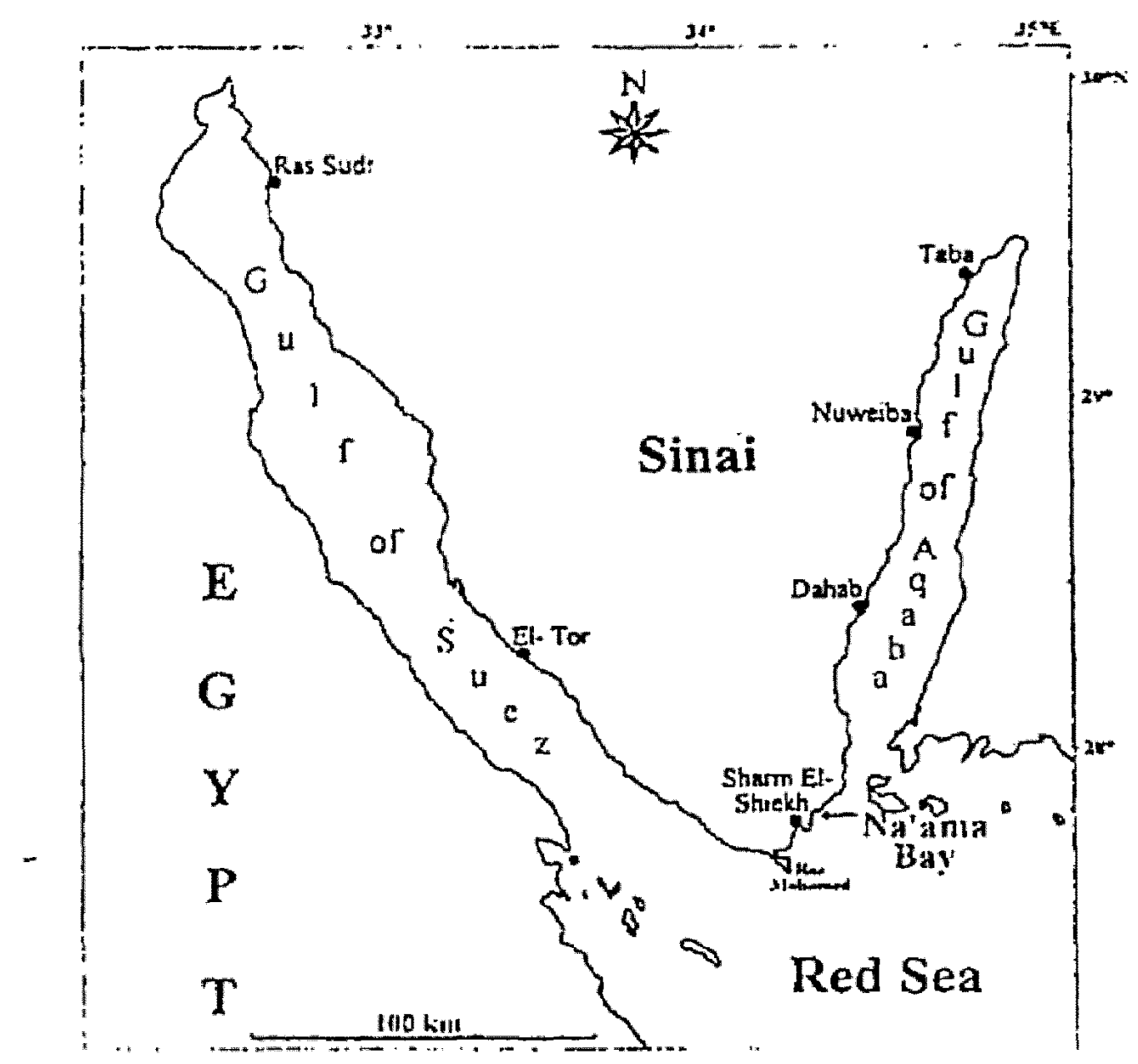

ure 1: The location of the study site (Natama Bay) in Sharm El-Shickly Area at the southern Sinai Peninsula. 
GROWTH RATES OF THREE REEF-BLILDRIG CORAL IS: SPECIES IN THE NORTHERN RED SEA, EGYPT

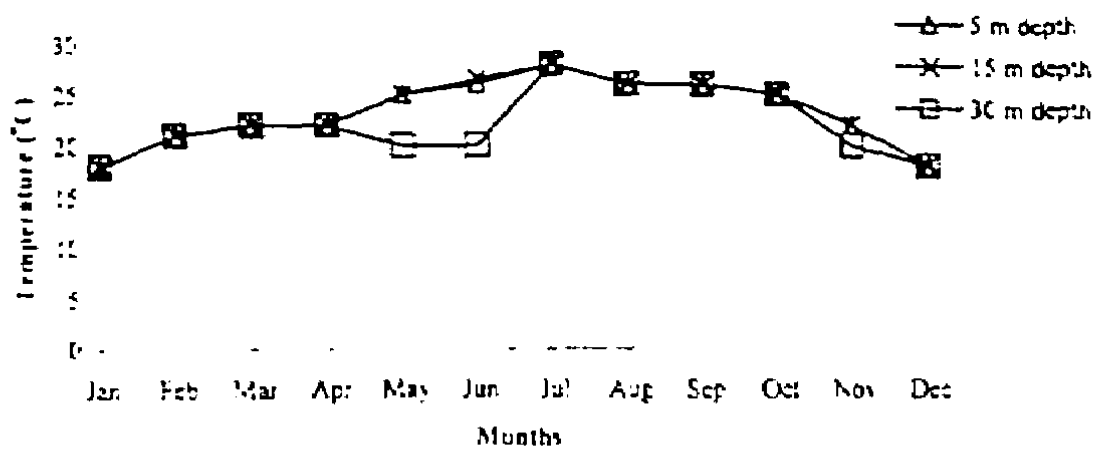

Figure 5: Montinly variation of temperature measured a: the investigated depths in the sludy aren

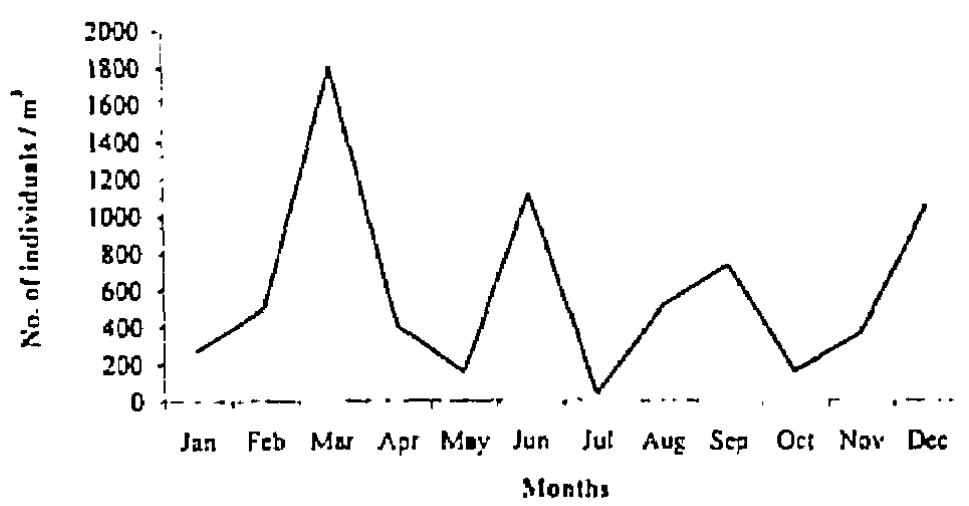

Figure 6: Monthly variation of plankton abundance al the surface water of the study arca.

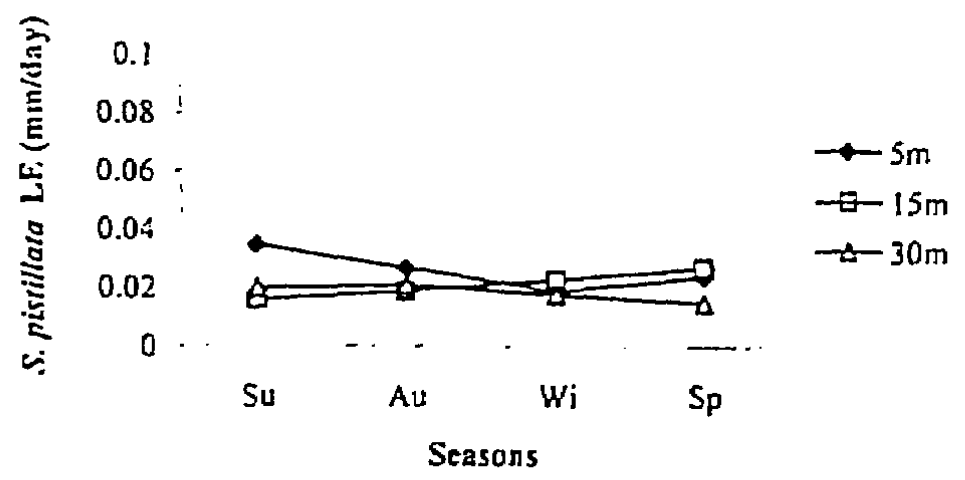

Figure 7: Linear extension rates of $S$ p:stillaro in differen: seasons a: different depths. $S u=$ summer, $A u=$ autums, $W i=$ winter, and $S_{p}=$ spring. 


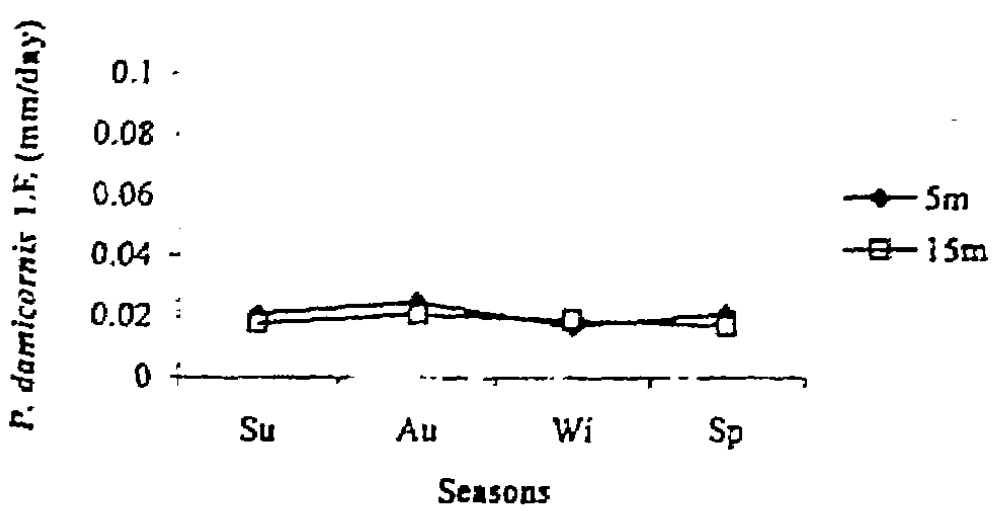

Figure 8: Linear extension rates of $P$. damicornis in different seasons at different depths. Su $=$ summer, $A u=$ aumumn, $W i=$ winter, and $S p=$ spring.

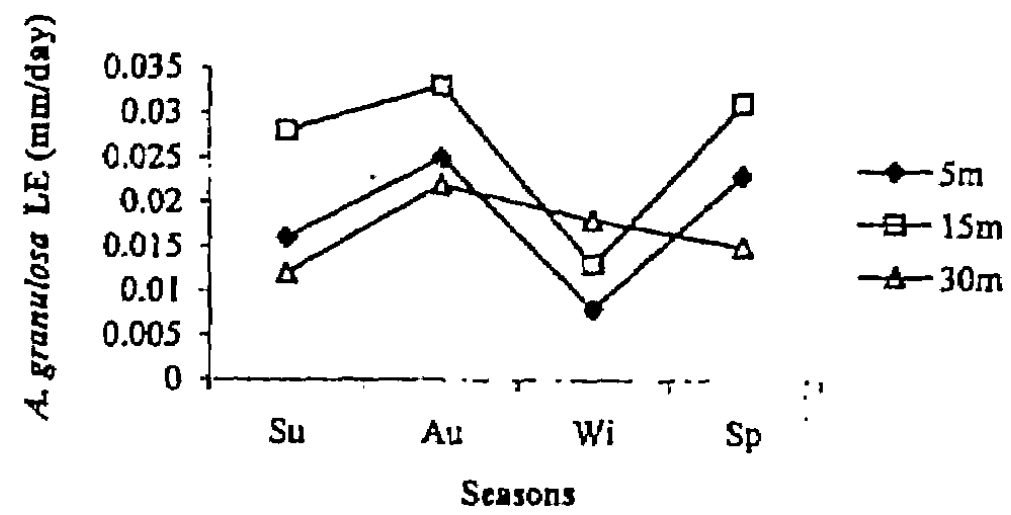

Figure 9: Linear extension rates of $A$. granulosa in different seasons at different depths. $S u=$ summer, $A u=$ sutumn, $W i=$ winter, and $S p=$ spring.

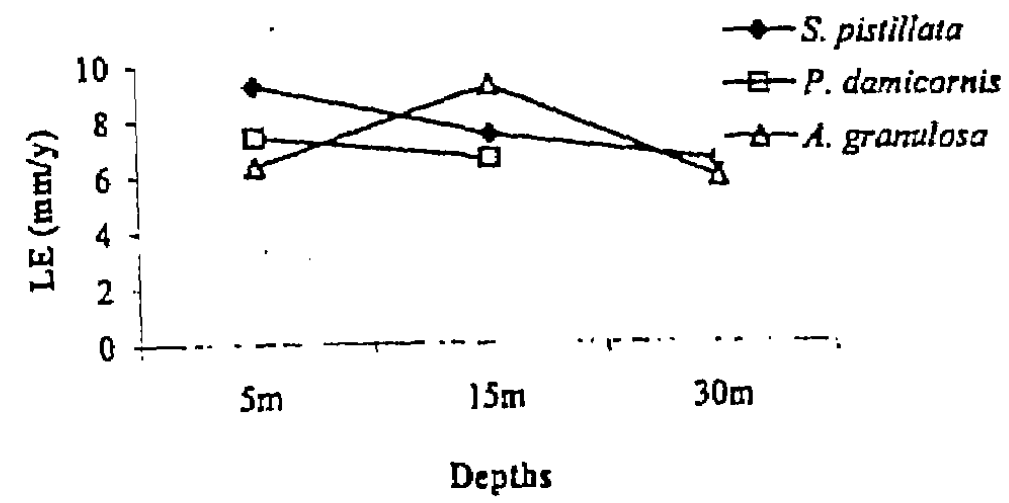

Figure 10: Annual linear extension rates of the different studied species at different depths. 